\title{
Covid-19 and kidney; a mini-review on current concepts and new data
}

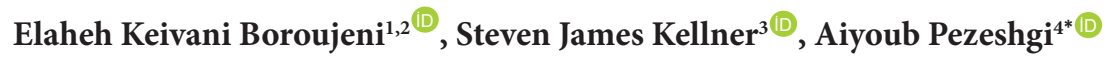 \\ ${ }^{1}$ Nickan Research Institute, Isfahan, Iran \\ ${ }^{2} 1901$ Augusta Dr. Apt 341, Zip Code 77057, Houston, Texas, USA \\ ${ }^{3}$ Mesencell Biotech International, Garth Business Centre, 193 Garth Road, Morden, United Kingdom \\ ${ }^{4}$ Department of Internal Medicine and Zanjan Metabolic Disease Research Center, School of Medicine, Zanjan University of Medical \\ Sciences, Zanjan, Iran
}

\section{A R T I C L E I N F O \\ Article Type: \\ Mini Review \\ Article History: \\ Received: 1 May 2020 \\ Accepted: 17 May 2020 \\ Published online: 27 May 2020}

\section{Keywords:}

COVID-19, Acute kidney injury, Acute respiratory distress syndrome, Acute lung injury, Chronic kidney disease, Multiple organ failure, Endstage renal disease

\begin{abstract}
A B S T R A C T
In late December 2019, some cases of acute respiratory illness occurred in Wuhan, Hubei province, China that caused by a virus named "severe acute respiratory syndrome 2" (SARS-Cov2). More susceptible patients to this disease are elderly male patients since these patients with comorbid diseases are disposed to severe infection and more death. The most important comorbid diseases with COVID-19 pneumonia are hypertension, diabetes mellitus, cerebrovascular disease, chronic obstructive pulmonary disease, coronary heart disease. The most common symptoms of SARSCov2 infection are dyspnea, cough, fatigue, diarrhea and vomiting. High number of kidney disease in hospitalized patients with COVID-19 has been reported. Furthermore, a large group of patients with COVID-19 pneumonia had signs of kidney disease, with a high level of serum creatinine and blood urea nitrogen that could be justified with different pathophysiologies happened in COVID-19 pneumonia. However, massive differences were found in the prevalence of acute kidney injury (AKI) in patients with acute respiratory distress syndrome (ARDS) secondary to COVID-19 pneumonia, since various studies have shown that AKI correlates with higher mortality rate, upper morbidity and more severe cases of illness. Therefore, we should be informed about the pathophysiology of AKI in COVID-19 pneumonia to find the modalities to decrease the incidence of AKI and subsequent decrease mortality and morbidity of this disease.
\end{abstract}

\section{Implication for health policy/practice/research/medical education:}

Renal failure on hospital admission of COVID-19 patients is a poor prognostic factor which increases the mortality rate.

Please cite this paper as: Keivani Boroujeni E, Kellner SJ, Pezeshgi A. COVID-19 and kidney; a mini-review on current concepts and new data. J Nephropharmacol. 2021;10(1):e01. DOI: 10.34172/npj.2021.01.

\section{Introduction}

In late December 2019, a series of unknown origin cases of acute respiratory illness detected in Wuhan, Hubei province, China $(1,2)$. High throughput sequencing showed that the disease was caused by a virus named "severe acute respiratory syndrome 2" (SARS-Cov2) (3). On $11^{\text {th }}$ February 2020, WHO officially changed the name of the disease caused by SARS-Cov2 to coronavirus disease 2019 (COVID-19). The disease rapidly spread from Wuhan to other parts of the world. It is reported that COVID-19 has much more infectivity than its ancestors, SARS and Middle East respiratory syndrome (MERS), however it has less mortality rate (4).

Genomic analysis of coronavirus sequence revealed that the amount of similarity between SARS-CoV genome of bats and SARS-Cov2 was about $96.2 \%$. It is suggested that SARS-Cov2 might be originated from bats (5). Other studies showed that SARS-CoV isolated from pangolin's body while SARS-Cov2 from human have 99\% similarity showing that pangolins might be a potential host for this virus (6). According to genomic sequencing studies, SARS-Cov2 has $79.5 \%$ similarity to the SARS-CoV virus, suggesting that they might have the same risk factors and mortality (7). The median age of the patients infected with SARS-CoV2 infection was 47 years old. Around $87 \%$ of patients with COVID-19 pneumonia were $30-79$ years old while $3 \%$ were 80 years old or older, and $41.9 \%$ of them were female $(7,8)$. The overall fatality rate in $70-79$-yearold patients was $2.3 \%$ while it was $14.8 \%$ in older than 80-year-old patients (8).

This finding implies that more susceptible patients to this disease are elderly male ones (2). In addition, patients 
with comorbid diseases are disposed to severe infection and more death rate $(9,10)$.

The most important comorbid diseases with COVID-19 pneumonia are hypertension, diabetes mellitus, cerebrovascular disease, chronic obstructive pulmonary disease and coronary heart disease $(7,11)$.

Other comorbidities such as cancer, chronic kidney disease (CKD), chronic liver disease, and diseases of gastrointestinal tract and nervous system also have been reported in patients with COVID-19 $(11,12)$.

There is already extensive evidence of extra-pulmonary involvement in Covid-19 pneumonia such as heart, kidney, and liver involvement (12).

The aim of this mini-review is discussing the pathophysiology of COVID-19 and kidney complications caused by it which may affect patient's prognosis.

\section{Transmission ways of SARS-CoV2}

1. Close contact (The most usual way of infection).

2. Transmission via aerosols.

3. Digestive tract could be a possible way of SARS-CoV2 infection (13).

4. SARS-CoV2 has been found in gastrointestinal tissue from COVID-19 patients (14).

5. SARS-CoV2 has been identified in tears and conjunctival secretions of COVID-19 patients (15).

\section{Clinical manifestations}

The most common symptoms of COVID-19 pneumonia are diffuse alveolar damage, acute respiratory failure and also, involvement of other organs in some cases (12).

The most common symptoms of SARS-CoV2 infection are dyspnea $(87.9 \%)$, cough $(67.7 \%)$, fatigue $(30.1 \%)$, diarrhea $(3.7 \%)$ and vomiting $(5 \%)(2,7,16)$.

Moreover, in severe cases of COVID-19, the complications pneumonia such as acute respiratory distress syndrome (ARDS), acute lung injury and secondary infections are also common (11). Other complications such as neurological damage (17), ocular surface infection (18), cardiac arrhythmia, renal damage and abnormal liver function tests $(12,18-20)$ are also usual in coronavirus infected patients.

Laboratory examinations in number of patients revealed $82.1 \%$ lymphopenia and $33.7 \%$ thrombocytopenia. Besides, the elevated levels of C-reactive protein, $\mathrm{LDH}$, and creatine phosphokinase $(\mathrm{CPK})$ were also found in their blood test. The majority of patients had normal leukocyte count, however, leukopenia was detected in $33.7 \%$ of them. Accordingly, a minority of patients had a high level of transaminase, or a raised serum creatinine levels $(4,21)$.

In some studies, various types of renal diseases in hospitalized individuals with COVID-19 were observed. Additionally, forty-percent of patients had signs of renal disease, with a high level of blood urea nitrogen and serum creatinine (around 13\% of patients) $(21,22)$. However, many differences were found in the prevalence of acute kidney injury (AKI) in patients with ARDS secondary to COVID-19 pneumonia (23). In some researches on small subsets of patients with COVID-19 pneumonia, they found hematuria and proteinuria were the most common features in $40 \%$ of admitted patients $(18,24)$.

Abdominopelvic CT scan revealed abnormal renal imaging (reduced density) in these patients, suggesting the existence of inflammation and edema in the patient's kidneys $(21,25)$.

Pathophysiology of renal involvement following COVID-19

1. After lung infection, COVID-19 RNA was detected in the serum of $15 \%$ of patients by RT-PCR (reverse transcription-polymerase chain reaction). This finding reveals that the virus may enter the blood and reside in renal tissue due to the high expression of ACE2 in renal cells and then damage to the resident renal cells (12).

2. Underlying inflammatory state in CKD patients might prone them to COVID-19 pneumonia due to pro-inflammatory state with function defect in adaptive and innate immune cell population (26) which increases the risk of pneumonia and also upper respiratory tract infection (27).

3. In COVID-19 pneumonia patients, superimposed infections during intensive care unit (ICU) stay may occur. The lipopolysaccharide expressed on the membrane of gram-negative bacteria metabolized by enzymes in the blood and released endotoxin which can cause septic shock. Secondary bacterial infection occurs in severe COVID-19 pneumonia and induces AKI then acts synergistically with other mechanisms of kidney damage through this mechanism (7). Moreover, low levels of $\mathrm{O}_{2}$ saturation in secondary bacterial pneumonia cause renal hypoxia and accelerates the development AKI (28).

4. The recent finding has confirmed a close relationship between alveolar and tubular damage (lung-kidney axis) in ARDS. A study on patients with ARDS with no previous acute or chronic kidney disease has detected that the pneumonia is the cause of ARDS in $83 \%$ of patients and AKI in $68 \%$ of cases. AKI was more severe in older age, higher body mass index, diabetes mellitus, chronic heart failure and higher airway peak pressure (29). ARDS also causes renal medullary hypoxia which makes additional insult to tubular cells (30).

5. Cytokine storm associated with COVID-19 pneumonia has been accompanied by elevated serum levels of interleukin-1 $\beta$ (IL-1 $\beta$ ), IL-2, IL7, IL-8, IL-9, IL-5, interferon- $\gamma$, tumor necrosis factor alpha (TNF- $\alpha$ ), G-CSF (granulocyte colonystimulating factor) and GM-CSF (granulocytemacrophage colony-stimulating factor) that resulted 
in an inflammatory response and subsequently tissue damages such as pulmonary edema (12). Therefore, AKI at this condition could be a result of body inflammation, increased vascular permeability, volume depletion and cardiomyopathy which can lead to cardio-renal response (31). Additionally, these mediators might exert deleterious effect on renal tissue through induction of shock, rhabdomyolysis following tissue hypoxia, and an elevated level of CPK in patients admitted to ICU $(1,21,32)$. This syndrome includes systemic endothelial injury which makes pleural effusion, edema, intra-abdominal hypertension, third space fluid loss, intravascular fluid depletion and hypotension (31).

6. Kidney microscopic specimens from patients with pneumonia of SARS-Cov2 who were accompanied by AKI, had a normal glomerular feature with lack of electron-dense deposits. This finding is against the diagnosis of glomerulonephritis mediated by immune complexes (33). Moreover, it has been reported that in the kidney, ACE-2 receptors are highly expressed in the brush border of the proximal tubular cells and less expressed in podocyte cells but not in the glomerular endothelial and mesangial cells (33). Therefore, it seems that, the virus has less capacity to infect glomeruli and has more capacity to infect tubules and podocytes.

7. Coronavirus binds to ACE-2 receptor via "S" protein on its surface as a cell entry receptor and then cleaved by cellular transmembrane serine proteases (TMPRSS) allowing the virus to release fusion peptide for membrane fusion (34), a condition which is similar to SARS-CoV which was reported in 2003. In this regard, the human tissue RNA sequencing data showed that, the affinity of " $S$ " spike for binding to ACE2 receptor in SARS-CoV2 is above 10-fold higher than SARS-CoV $(35,36)$. Obviously, SARS$\mathrm{CoV}$ was not detectable in any of the analyzed patient's renal specimen which means that renal impairment is likely due to both multiple organ failure and cytokine release syndrome $(33,37)$ rather than active viral infection in the kidney. However, the human kidney is a specific target for SARS-CoV2 infection (38). Recently, the viral nucleocapsid protein was detected in the kidney of infected patients. It was also showed that SARS-CoV2 antigen accumulated in the kidney tubules suggesting that SARS-CoV2 directly infects the human kidney and induces AKI and also contributes to spreading the virus in the body. The difference between the higher renal tropism of SARS$\mathrm{CoV} 2$ versus SARS-CoV could be explained by the increased affinity of SARS-CoV2 to ACE-2 receptor that is allowing greater interfection of the kidney which may act as a viral reservoir (39).

A study on cells of 15 normal kidneys showed high colonization of ACE-2 and TMPRSS on podocytes and in proximal straight tubule cells, identified the kidney as a candidate host cells (40).

Human RNA sequencing demonstrates that ACE-2 receptor expression in the kidney is about a hundredfold more than that of the lung (18), however renal involvement in COVID-19 pneumonia is much less than lung involvement (12). The etiology of this discrepancy is because of the lowest expression of AGTR2m-RNA in the kidney's tissue and the highest level in the lung's tissue, since it is a G-protein-coupled receptor which activates with ACE2/ Ag (1-7)/MasR axis (41).

\section{Outcome and prognosis}

Patients with a high level of serum creatinine at the time of admission were more likely to be admitted to ICU and treated by mechanical ventilation, showing that renal failure on admission is a poor prognostic factor and increases mortality rate $(21,42)$.

Generation of angiotensin-(1-7)[Ang-(1-7)], via Ag-II and ACE-II can create a safe environment in the lung for cells that may counterbalance vasoconstriction and profibrotic process (43). Hence, reduced ACE-2 expression increases Ag-II level trough AT1R that may aggravate the disease process, induce lung edema and impair respiratory function due to the fibrotic process and inflammation $(33,43,44)$.

COVID-19 pneumonia and end-stage renal disease Analysis of a peripheral blood sample in ESRD (endstage renal disease) individuals infected with SARS-CoV2 showed lower levels of T-cells, T-helper cells, cytotoxic T-cells and NK-cells. Likewise, the serum levels of inflammatory cytokines in ESRD patients were lower than patients with COVID-19 pneumonia and normal renal function (45). Therefore, the prognosis of COVID-19 pneumonia in ESRD patients was much better than others while the rate of ARDS and severe lung involvement was lower which may be attributed to lower severity of cytokine storm. However, it is suggested that hemodialysis patients have a higher chance for SARS-CoV2 infection; therefore additional prevention tools seem logical in handling the epidemic in hemodialysis patients (45). Various infections including viral infections are associated with high levels of oxidative stress and inflammation. Therefore, some antioxidants might be useful in these patients $(44,45)$.

\section{Conclusion}

Various studies have shown that AKI correlates with higher mortality rate, upper morbidity and more severe case of illness. Therefore, we should be informed about the pathophysiology of AKI in COVID-19 pneumonia to find ways to decrease the incidence of AKI and subsequent decrease mortality and morbidity due to this disease.

Authors' contribution

EK prepared the primary draft. AP conducted the extensive 
revision. JSK conducted the final edit. All authors gave final approval for publication.

\section{Conflicts of interest}

The authors declare no conflicts of interest.

Ethical considerations

Ethical issues (including plagiarism, data fabrication, double publication) have been completely observed by the authors.

\section{Funding/Support}

None.

\section{References}

1. Bai Y, Yao L, Wei T, Tian F, Jin DY, Chen L, et al. Presumed Asymptomatic Carrier Transmission of COVID-19. JAMA. 2020 Feb 21. doi: 10.1001/jama.2020.2565.

2. Zhu N, Zhang D, Wang W, Li X, Yang B, Song J. A Novel Coronavirus from Patients with Pneumonia in China, 2019. N Engl J Med. 2020;382:727-733. doi: 10.1056/ NEJMoa2001017.

3. Lu R, Zhao X, Li J, Niu P, Yang B, Wu H, et al. Genomic characterisation and epidemiology of 2019 novel coronavirus: implications for virus origins and receptor binding. Lancet. 2020;395:565-574. doi: 10.1016/S01406736(20)30251-8.

4. Rodriguez-Morales AJ, Cardona-Ospina JA, GutiérrezOcampo E, Villamizar-Peña R, Holguin-Rivera Y, EscaleraAntezana JP. Clinical, laboratory and imaging features of COVID-19: A systematic review and meta-analysis. Travel Med Infect Dis. 2020:101623. doi: 10.1016/j. tmaid.2020.101623.

5. Benvenuto D, Giovanetti M, Salemi M, Prosperi M, De Flora C, Junior Alcantara LC, etal. The global spread of 2019-nCoV: a molecular evolutionary analysis. Pathog Glob Health. 2020;114:64-67. doi: 10.1080/20477724.2020.1725339.

6. Xu X, Chen P, Wang J, Feng J, Zhou H, Li X, et al. Evolution of the novel coronavirus from the ongoing Wuhan outbreak and modeling of its spike protein for risk of human transmission. Sci China Life Sci. 2020;63:457-460. doi: 10.1007/s11427-020-1637-5.

7. Guan WJ, Zhong NS. Clinical characteristics of COVID-19 in China. Reply. N Engl J Med. 2020;382:1859-62. doi:10.1056/NEJMc2005203

8. Wu Z, McGoogan JM. Characteristics of and important lessons from the coronavirus disease 2019 (COVID-19) outbreak in China: summary of a report of 72314 cases from the Chinese Center for Disease Control and Prevention. JAMA. 2020;323:1239-1242. doi:10.1001/jama.2020.2648

9. Wang L, He W, Yu X, Hu D, Bao M, Liu H, et al. Coronavirus disease 2019 in elderly patients: Characteristics and prognostic factors based on 4-week follow-up. J Infect. 2020;80(6):639-645. doi: 10.1016/j.jinf.2020.03.019.

10. Zhou F, Yu T, Du R, Fan G, Liu Y, Liu Z. Clinical course and risk factors for mortality of adult inpatients with COVID-19 in Wuhan, China: a retrospective cohort study.Lancet. 2020;395:1054-1062. doi: 10.1016/S0140-6736(20)30566-3.

11. Chen N, Zhou M, Dong X, Qu J, Gong F, Han Y, et al.
Epidemiological and clinical characteristics of 99 cases of 2019 novel coronavirus pneumonia in Wuhan, China: a descriptive study. Lancet. 2020;395:507-513. doi: 10.1016/ S0140-6736(20)30211-7.

12. Huang C, Wang Y, Li X, Ren L, Zhao J, Hu Y, et al. Clinical features of patients infected with 2019 novel coronavirus in Wuhan, China. Lancet. 2020;395:497-506. doi: 10.1016/ S0140-6736(20)30183-5.

13. Wang J, Zhao S, Liu M, Zhao Z, Xu Y, Wang P, et al. ACE2 expression by colonic epithelial cells is associated with viral infection, immunity and energy metabolism. medRxiv. 2020. doi: 10.1101/2020.02.05.20020545.

14. Xiao F, Tang $M$, Zheng $X$, Liu $Y$, Li $X$, Shan $H$. Evidence for Gastrointestinal Infection of SARSCoV-2. Gastroenterology. 2020 Mar 3. doi: 10.1053/j. gastro.2020.02.055.

15. Xia J, Tong J, Liu M, Shen Y, Guo D. Evaluation of coronavirus in tears and conjunctival secretions of patients with SARS-CoV-2 infection. J Med Virol. 2020 Feb 26. doi: 10.1002/jmv.25725.

16. Ho LTF, Chan KKH, Chung VCH, Leung TH. Highlights of traditional Chinese medicine frontline expert advice in the China national guideline for COVID-19. Eur J Integr Med. 2020;36:101116. doi: 10.1016/j.eujim.2020.101116.

17. Mao L, Jin H, Wang M, Hu Y, Chen S, He Q. Neurologic manifestations of hospitalized patients with coronavirus disease 2019 in Wuhan, China. JAMA Neurol. 2020 Apr 10. doi: 10.1001/jamaneurol.2020.1127.

18. Li Z, Wu M, Yao J, Guo J, Liao X, Song S, et al. Caution on Kidney Dysfunctions of COVID-19 Patients. medRxiv; 2020. doi: 10.1101/2020.02.08.20021212.

19. Wang D, Hu B, Hu C, Zhu F, Liu X, Zhang J, et al. Clinical characteristics of 138 hospitalized patients with 2019 novel coronavirus-infected pneumonia in Wuhan, China. AMA. 2020;323:1061-1069. doi: 10.1001/jama.2020.1585

20. Xu Z, Shi L, Wang Y, Zhang J, Huang L, Zhang C, et al. Pathological findings of COVID-19 associated with acute respiratory distress syndrome. Lancet Respir Med. 2020;8:420-422. doi: 10.1016/S2213-2600(20)30076-X.

21. Cheng Y, Luo R, Wang K, Zhang M, Wang Z, Dong L, et al. Kidney disease is associated with in-hospital death of patients with COVID-19. Kidney Int. 2020;97:829-838. doi: 10.1016/j.kint.2020.03.005. Epub 2020 Mar 20.

22. Fan C, Li K, Ding Y, Lu Lu W, Wang J. ACE2 expression in kidney and testis may cause kidney and testis damage after 2019-nCoV Infection. medRxiv 2020. doi: doi:10.1101/2020.02.12.20022418

23. Wu C, Chen X, Cai Y, Xia J, Zhou X, Xu S, et al. Risk factors associated with acute respiratory distress syndrome and death in patients with coronavirus disease 2019 pneumonia in Wuhan, China. JAMA Intern Med. 2020 Mar 13. doi: 10.1001/jamainternmed.2020.0994.

24. Wang L, Li X, Chen $\mathrm{H}$, et al. Coronavirus disease 19 infection does not result in acute kidney injury: an analysis of 116 hospitalized patients from Wuhan, China. Am J Nephrol. 2020;51:343-348. doi:10.1159/000507471.

25. Hong XW, Chi ZP, Liu GY, Huang H, Guo SQ, Fan JR, et al. Analysis of early renal injury in COVID-19 and diagnostic value of multi-index combined detection. medRxiv 2020. doi: 10.1101/2020.03.07.20032599 
26. Betjes MG. Immune cell dysfunction and inflammation in end-stage renal disease. Nat Rev Nephrol. 2013;9:255-65. doi: 10.1038/nrneph.2013.44.

27. Eskandari Naji H, Ghorbanihaghjo A, Argani H, Raeisi S. Serum sTWEAK and FGF-23 Levels in Hemodialysis and Renal Transplant Patients. Int J Organ Transplant Med. 2017;8:110-116.

28. Wan S, Yi Q, Fan S, Jinglong Lv, Zhang X, Guo L, et al. Characteristics of lymphocyte subsets and cytokines in peripheral blood of 123 hospitalized patients with 2019 novel coronavirus pneumonia (NCP). medRxiv 2020. doi: 10.1101/2020.02.10.20021832

29. Panitchote A, Mehkri O, Hastings A, Hanane T, Demirjian $\mathrm{S}$, Torbic $\mathrm{H}$, et al. Factors associated with acute kidney injury in acute respiratory distress syndrome. Ann Intensive Care. 2019;9:74. doi: 10.1186/s13613-019-0552-5.

30. Husain-Syed F, Slutsky AS, Ronco C. Lung-kidney crosstalk in the critically Ill patient. Am J Respir Crit Care Med. 2016;194(4):402-14. doi: 10.1164/rccm.201602-0420CP.

31. Ronco C, Reis T. Kidney involvement in COVID-19 and rationale for extracorporeal therapies. Nat Rev Nephrol. 2020. doi: 10.1038/s41581-020-0284-7.

32. Kumar A, Zarychanski R, Pinto R, Cook DJ, Marshall J, Lacroix J, et al. Critically ill patients with 2009 influenza A(H1N1) infection in Canada. JAMA. 2009;302:1872-9. doi: 10.1001/jama.2009.1496.

33. Chu KH, Tsang WK, Tang CS, Lam MF, Lai FM, To KF, et al. Acute renal impairment in coronavirus-associated severe acute respiratory syndrome. Kidney Int. 2005;67(2):698705.

34. Zhang H, Penninger JM, Li Y, Zhong N, Slutsky AS. Angiotensin-converting enzyme 2 (ACE2) as a SARSCoV-2 receptor: molecular mechanisms and potential therapeutic target. Intensive Care Med. 2020;46:586-590. doi: 10.1007/s00134-020-05985-9.

35. Zhou P, Yang XL, Wang XG, Hu B, Zhang L, Zhang W, et al. A pneumonia outbreak associated with a new coronavirus of probable bat origin. Nature. 2020;579(7798):270-273. doi: 10.1038/s41586-020-2012-7.

36. Wrapp D, Wang N, Corbett KS, Goldsmith JA, Hsieh CL,
Abiona O, et al. Cryo-EM structure of the 2019-nCoV spike in the prefusion conformation. Science. 2020;367:12601263. doi: 10.1126/science.abb2507.

37. Tisoncik JR, Korth MJ, Simmons CP, Farrar J, Martin TR, Katze MG. Into the eye of the cytokine storm. Microbiol Mol Biol Rev. 2012;76:16-32. doi: 10.1128/MMBR.0501511.

38. Diao B, Feng Z, Wang C, Wang H, Liu L, Wang C, et al. Human kidney is a target for novel severe acute respiratory syndrome coronavirus 2 (SARS-CoV-2) infection. Medrxiv 2020. doi: 10.1101/2020.03.04.20031120.

39. Wan Y, Shang J, Graham R, Baric RS, Li F. Receptor Recognition by the Novel Coronavirus from Wuhan: an Analysis Based on Decade-Long Structural Studies of SARS Coronavirus. J Virol. 2020;94:e00127-20. doi: 10.1128/ JVI.00127-20.

40. Pan XW, Xu D, Zhang H, Zhou W, Wang LH, Cui XG. Identification of a potential mechanism of acute kidney injury during the COVID-19 outbreak: a study based on single-cell transcriptome analysis. Intensive Care Med. 2020 Mar 31. doi: 10.1007/s00134-020-06026-1.

41. Guo L, Yu K, Li D, Yang H, Liu L, Fan J, et al. Potential Pathogenesis of Multiple Organ Injury in COVID-19. Preprints 2020. doi: 10.20944/preprints202003.0308.v1.

42. Giuseppe L, Camilla M, Fabian SG, Brandon MH. Clinical and demographic characteristics of patients dying from COVID-19 in Italy versus China. Journal J Med Virol. doi: 10.1002/jmv. 25860

43. Kuba K, Imai Y, Rao S, Gao H, Guo F, Guan B, et al. A crucial role of angiotensin converting enzyme 2 (ACE2) in SARS coronavirus-induced lung injury. Nat Med. 2005;11:875-9.

44. Forouzesh M, Rahimi Azadeh, Valizadeh R, Dadashzadeh $\mathrm{N}$, Mirzazadeh A. Clinical display, diagnostics and genetic implication of novel coronavirus (COVID-19). Eur Rev Med Pharmacol Sci 2020;24:4607-4615. doi: 10.26355/ eurrev_202004_21046.

45. Ma Y, Diao B, Lv X, Zhu J, Liang W, Liu L, et al. 2019 novel coronavirus disease in hemodialysis (HD) patients: report from one HD center in Wuhan, China. medRxiv. 2020 Feb. doi: $10.1101 / 2020.02 .24 .20027201$

Copyright $\odot 2021$ The Author(s); Published by Published by Society of Diabetic Nephropathy Prevention. This is an open-access article distributed under the terms of the Creative Commons Attribution License (http://creativecommons.org/licenses/by/4.0), which permits unrestricted use, distribution, and reproduction in any medium, provided the original work is properly cited. 